\title{
Residual complaints of patients two years after severe head injury
}

\author{
AH VAN ZOMEREN, W VAN DEN BURG \\ From the Departments of Neurology and Clinical Psychology, Neuropsychology Unit, University Hospital, \\ Groningen, The Netherlands
}

SUMmARY In a follow up study of 57 patients who had sustained a severe closed head injury, $84 \%$ still reported some residual deficit in their psychological functioning after two years, with forgetfulness being the most common complaint. Expressing the severity of the injury in terms of both the duration of post-traumatic amnesia (PTA) and the extent to which previous work could be resumed (RTW), principal components analyses showed that the occurrence of "impairment complaints"-viz forgetfulness, slowness, poor concentration and inability to divide attention over two simultaneous activities - was positively related to severity. The other complaints, which in the main could be labelled as "intolerances" were not. The same pattern was found when the analyses were based on deficits of the patients as they were reported by relatives. Severity was not appreciably related to the total number of complaints. The correlation between PTA and RTW was 0.52 , indicating that with longer PTA duration, work is likely to be resumed at a lower level, or not at all. Though Russell's cut-off of one week PTA to differentiate between severe and very severe concussion appeared useful, in the present study a further cut-off point at the unlucky number of 13 days was considered.

The head-injured patient can be viewed as a relative expert in the field of head injury, and examining his or her complaints more fully can serve two goals: firstly, a description of post-traumatic states cannot be complete if the subjective aspects are neglected; secondly, listening to the patient might be helpful in generating hypotheses about the nature of the deficits, hypotheses that can be tested within an experimental psychological framework. The studies to date indicate that after head injury, people may mention a large variety of complaints, such as headache, dizziness, poor memory, poor concentration, fatigue, irritability and anxiety. The majority of these investigations, however, have studied patients who had sustained minor or moderately severe head injuries, with PTA durations of up to a few days. ${ }^{1-4}$ The search for stable combinations of complaints, which would justify the word "syndrome" has, however, not been successful with such patients. Lidvall ${ }^{1}$ used the word "polymorphous" when describing the symptom pic-

Address for reprint requests: AH van Zomeren, Department of Neurology, University Hospital, Oostersiugol 59, 9713 EZ Groningen, The Netherlands.

Received 16 January 1984, and in revised form 6 April 1984. Accepted 19 June 1984 ture of patients who reported complaints lasting more than two weeks after minor injuries.

A few studies on patients who had sustained severe cerebral concussion are available. Oddy et al. ${ }^{5}$ described a group of 50 young adults with a PTA exceeding 24 hours. When these subjects were interviewed six months after their accidents, less than a quarter of them claimed to be symptom-free. The remaining patients reported the following complaints: trouble remembering things (38\%), often losing temper $(35 \%)$, becoming tired very easily $(33 \%)$, having difficulty concentrating when reading $(29 \%)$, often irritable $(29 \%)$, often impatient $(27 \%)$, often restless $(27 \%)$, and finding difficulty in becoming interested in anything $(21 \%)$. McKinlay et $a^{6}$ studied psychological changes in patients after a severe head injury by reviewing close relatives of 55 adults who had suffered PTA for two days or longer. Interviews took place at 3,6 and 12 months after injury and on the last occasion, six problems were mentioned with high frequencies. These problems were: irritability $(71 \%)$, impatience $(71 \%)$, tiredness $(69 \%)$, poor memory $(69 \%)$, slowness $(67 \%)$ and bad temper $(67 \%)$. These two studies clearly indicate that six or even twelve months after a severe head injury complete recovery is seldom the rule. 
One purpose of the present investigation was to make an inventory of the situation two years after injury, as well as to assess whether the complaints most frequently mentioned would be similar to those reported in other studies. ${ }^{56} \mathrm{~A}$ second purpose was to relate the severity of injury to complaining. This relationship has been studied in almost all of the aforementioned investigations. Neurological signs and symptoms in early stages after injury have been correlated with complaints at follow-up, either with the mere fact that complaints existed, or with the actual number of complaints reported. While sometimes no relation was found, ${ }^{14}$ other studies showed a positive relationship. ${ }^{23}$ In the study of 50 severely injured patients carried out by Oddy $e t$ al, ${ }^{5}$ the number of complaints six months after injury showed a weak but positive association with PTA $(r=0.30)$ and time before return to work $(r=0 \cdot 27)$. A negative relation was observed by Miller ${ }^{78}$ who concluded that one third of his patients seen for medico-legal assessment had complaints indicating a neurotic disability that was inversely related to the actual severity of the injury. This "accident neurosis" disappeared as soon as the compensation issue was settled. Kelly, ${ }^{9}$ however, pointed out that iatrogenic factors may play a role in seemingly neurotic complaining, and the finding about the effect of financial compensation was not confirmed in later investigations. ${ }^{5} 1011$

In the present study, severity of injury is not only expressed in the neurological measure PTA, but also in terms of social outcome, that is the extent to which previous work could be resumed (return to work = RTW). Complaints will be correlated with both PTA and RTW and, in addition, the usefulness of the Russell dichotomy ${ }^{12}$ of severe versus very severe concussions with 7 days as a cut-off point will be evaluated on the basis of these data.

\section{Methods}

\section{Subjects}

Fifty-four males and seven females, admitted to the Department of Neurology between September 1978 and July 1979 with a severe closed head injury were asked, during their stay in the hospital, to participate in a neuropsychological follow-up study. All 61 agreed to take part. The group contained no patients with depressed fractures of the skull, since such patients are admitted to the Department of Neurosurgery. Due to this selection process, aphasic symptoms were rare in the acute stage and virtually absent at the time of follow-up. Excluded from the study were patients younger than 15 and older than $60 \mathrm{y}$, as well as patients with a PTA of less than two hours. Duration of PTA was defined as the interval from the moment of injury until the return of continuous day-to-day memory. ${ }^{1314}$ The end of PTA for each patient was assessed by one of the authors by means of a standardised questionnaire which was completed daily. Two years after the injury each patient was
Table 1 Frequencies of residual complaints, expressed in percentages, in a group of 57 patients questioned two years after a severe closed head injury

\begin{tabular}{ll}
\hline & $\%$ \\
\hline forgetfulness & 54 \\
irritability & 39 \\
slowness & 33 \\
poor concentration & 33 \\
fatigue & 30 \\
dizziness & 26 \\
increased need of sleep & 25 \\
intolerance of glaring light & 25 \\
intolerance of noise & 23 \\
loss of initiative & 23 \\
headache & 23 \\
crying more readily & 21 \\
unable to do two things simultaneously & 21 \\
intolerance of bustle & 19 \\
depressed mood & 19 \\
more anxious & 18 \\
indifference & 16 \\
\hline
\end{tabular}

invited by post to visit the Department for the follow-up interview and psychological assessment. Fifty-seven patients responded, 51 men and six women. Their mean age at the time of the injury was 26.6 y (SD $12.2 \mathrm{y}$, range 15-59 y). The majority $(93 \%)$ had been in PTA for at least one day, whilst 39 of the patients $(68 \%)$ had a PTA of more than one week which rates as very severe concussion in the Russellclassification. ${ }^{12}$ Mean PTA duration was 30.5 days (SD 36.5, range 0-169 days) but the distribution was highly skewed, $\stackrel{\oplus}{\oplus}$ the median being 22.0 days. For that reason a logarithmic transformation was performed on duration of PTA beforeg using it in the statistical analyses.

\section{Questionnaire}

Residual complaints were assessed by means of a questione्ठ naire consisting of 17 items. These questions were chosen on the basis of the existing literature as well as on the authors' own experience with head-injured subjects. Only questions that clearly applied to the situation of all patients were included. For example, a question about intolerance of alcohol was excluded as it was noted that many patients stop drinking after a very severe cerebral concussion, often as a result of a doctor's advice. The 17 questions that were finally selected as being generally applicable are listed in table 1 . Patients were always asked to judge their present state in relation to their functioning before the injury. Clearly headache frequency after head injury by itself is not indicative of headache frequency consequent to head injury. This point has been stressed by Lidvall et $a l^{1}$ who go on to suggest that many of the controversies around the topic of post-traumatic neurotic reaction may well have arisen from a failure to distinguish between old and new complaints.

Special care was taken in phrasing the selected items. The questions were framed in simple language, and often a double formulation was used to ensure that subjects understood what the investigator was asking. For instance: "Do you have more trouble in concentrating or fixing your mind on things, than you had before the accident?" The questionnaire was filled out by the invesigator while interviewing the patient. Each answer was scored simply as 0 or 1, a complain being absent or present. 
After completing the questionnaire, subjects were asked to indicate the extent to which they had resumed their former work or study. Answers were graded on the following five-point scale, the variable Return to Work (RTW):

$0=$ former work or study resumed without any changes

1 = former work resumed, but with lower demands, for example part-time or at a lower rate

2 = former work not resumed; working at a lower level

3 = working in a socially sheltered environment

$4=$ not working at all.

Two patients could not be scored. The other 55 patients were distributed as follows on the scale: score $0-58 \%$; score $1-13 \%$; score 2-5\%; score 3-7\%; score 4-16\%.

In the final part of the session patients were asked to complete an extensive battery of tests. The aim of this testing was to assess their present neuropsychological state. Results of these tests will be published elsewhere.

\section{Results}

\section{Frequencies of complaints}

A large majority of the patients $(84 \%)$ reported some residual complaint. In table 1 the questionnaire items are listed along with the frequencies of confirmation in percentages. The items are rank-ordered according to these frequencies. Forgetfulness was by far the most frequent residual complaint. More than half of the group confirmed the question: "Do you think that generally speaking you forget more things now than you did before the accident?" The items with the lowest frequency of confirmation were questions relating to emotional changes that may occur after head injury.

\section{The complaints in relation to PTA and RTW}

A non-significant (Pearson) correlation of 0.11 was found between the total number of complaints and PTA. The number of complaints correlated significantly, but not appreciably, with RTW $(r=0.29, p<0.025)$. The correlation between PTA and RTW was, however, substantial: $r=0.54$ $(\mathrm{p}<0.001)$.

Table 2 contains the correlations with PTA and RTW for each single complaint. The overall picture suggests that only complaints concerning some impairments (forgetfulness, slowness and inability to do two things simultaneously) are connected with PTA and RTW, while the other complaints do not appear to be related.

Two subgroups of patients, however, might have obscured the actual relation between complaints and severity of injury. Firstly, there may be patients who, at first sight, appear to complain "too much". This group could, however, consist of either anxious complainers whose complaints have little to do with the head injury per se, or on the other hand, of keen observers who are able to detect subtle changes in
Table 2 Correlations between the presence of residual complaints, duration of PTA, and level of $R T W$ in a group of 57 patients

\begin{tabular}{lcc}
\hline & $P T A$ & $R T W$ \\
\hline forgetfulness & $0 \cdot 54^{*}$ & $0 \cdot 18$ \\
irritability & $0 \cdot 11$ & -0.08 \\
slowness & $0 \cdot 32^{*}$ & $0.36^{*}$ \\
poor concentration & $0 \cdot 16$ & 0.21 \\
fatigue & $0 \cdot 14$ & $0 \cdot 17$ \\
dizziness & $-0 \cdot 18$ & 0.04 \\
increased need of sleep & -0.25 & -0.07 \\
intolerance of glaring light & -0.19 & $0 \cdot 10$ \\
intolerance of noise & 0.07 & 0.22 \\
loss of initiative & 0.01 & 0.19 \\
headache & -0.16 & 0.02 \\
crying more readily & 0.06 & $0 \cdot 20$ \\
inability to do two things simultaneously & $0.33^{*}$ & $0.56^{*}$ \\
intolerance of bustle & 0.04 & 0.21 \\
depressed mood & 0.11 & 0.26 \\
more anxious & -0.08 & 0.06 \\
indifference & 0.03 & 0.04 \\
RTW & 0.54 & - \\
\hline
\end{tabular}

* = significant at $\mathrm{p}=00.05$ (two-sided)

themselves, changes which are not perceived by others and which are not picked up by the available psychological tests. No objective method of differentiating between anxious complainers and keen observers seems to exist.

Secondly, some very severely injured patients who lack insight into their own deficits may be present. Such patients would complain "too little". It was possible to identify this group objectively using three tests from the assessment battery, viz serial word learning, recognition of previously seen faces, and visual reaction time. Performance on these tests was contrasted with the answers given to questions concerning "forgetfulness" and "slowness". Using this procedure, five patients who clearly complained "too little" were identified and were excluded from any further analysis.

Table 3 contains the correlations between the questionnaire items, PTA and RTW for the selected group of 52 patients. Comparing the first two columns of this table with those of table 2 , an increase in the correlations with PTA and RTW can be noted for the items "forgetfulness", "slowness", "poor concentration" and "inability to do two things simultaneously". "Poor concentration" now shows a significant correlation with RTW and PTA. The suggestion that only impairment complaints are related to RTW and PTA is therefore strengthened.

This proposition is clearly corroborated and qualified, when a principal component analysis is performed on the correlation matrix of table 3 (See Note). The eigen-values for the first six principal components were: $5.48,2.32,1.58,1.36,1.20$ and 0.99 . Considering the so-called "scree criterion", 13 and also since PTA and RTW loaded appreciably on the first 
Table 3 Intercorrelations of residual complaints, PTA and RTW in a selected group of 52 patients

\begin{tabular}{|c|c|c|c|c|c|c|c|c|c|c|c|c|c|c|c|c|}
\hline \multirow[t]{2}{*}{$\begin{array}{l}\text { FF } \\
\text { IR } \\
\text { SL } \\
\text { CO } \\
\text { FA } \\
\text { DZ } \\
\text { SP } \\
\text { LI } \\
\text { NO } \\
\text { IN } \\
\text { HE } \\
\text { CR } \\
\text { TT } \\
\text { BU } \\
\text { DE } \\
\text { AN } \\
\text { ID }\end{array}$} & $\begin{array}{l}\text { RTW } \\
\text { forgetfulness } \\
\text { irritability } \\
\text { slowness } \\
\text { poor concentration } \\
\text { fatigue } \\
\text { dizziness } \\
\text { incr. need of sleep } \\
\text { intolerance of light } \\
\text { intolerance of noise } \\
\text { loss of initiative } \\
\text { headache } \\
\text { crying more readily } \\
\text { inability two things } \\
\text { intolerance of bustle } \\
\text { depressed mood } \\
\text { more anxious } \\
\text { indifference }\end{array}$ & $\begin{aligned} 0.50^{*} \\
0.55^{*} \\
0 \cdot 12 \\
0.37^{*} \\
0 \cdot 28^{*} \\
0 \cdot 17 \\
-0 \cdot 10 \\
-0.27 \\
-0.11 \\
0.09 \\
0.11 \\
-0.07 \\
0.07 \\
0.37^{*} \\
0.05 \\
0.24 \\
-0.08 \\
0.04\end{aligned}$ & $\begin{array}{c}0.26 \\
-0.04 \\
0.41^{*} \\
0.27 \\
0.20 \\
0.09 \\
-0.06 \\
0.16 \\
0.25 \\
0.26 \\
0.07 \\
0.23 \\
0.62^{*} \\
0.24 \\
0.34^{*} \\
0.07 \\
0.05\end{array}$ & $\begin{array}{r}0.23 \\
0.41 \\
0.46 \\
0.27 \\
0.26 \\
-0.10 \\
0.14 \\
0.23 \\
0.29 \\
0.10 \\
0.10 \\
0.28 \\
0.07 \\
0.32 \\
0.02 \\
0.29\end{array}$ & $\begin{array}{r}0.03 \\
0.39 \\
0.26 \\
0.30 \\
0.21 \\
0.43 \\
0.25 \\
0.20 \\
0.29 \\
0.29 \\
0.20 \\
0.44 \\
0.10 \\
-0.00 \\
0.04\end{array}$ & $\begin{array}{r}0.29 \\
0.41 \\
0.08 \\
0.17 \\
0.11 \\
0.39 \\
0.25 \\
-0.04 \\
0.34 \\
0.44 \\
0.19 \\
0.44 \\
0.04 \\
0.18\end{array}$ & $\begin{array}{l}0.53 \\
0.20 \\
0.20 \\
0.42 \\
0.42 \\
0.56 \\
0.27 \\
0.27 \\
0.47 \\
0.32 \\
0.36 \\
0.16 \\
0.31\end{array}$ & $\begin{array}{l}0.22 \\
0.32 \\
0.26 \\
0.54 \\
0.40 \\
0.30 \\
0.40 \\
0.40 \\
0.44 \\
0.39 \\
0.39 \\
0.33\end{array}$ & $\begin{array}{l}0.12 \\
0.45 \\
0.35 \\
0.18 \\
0.18 \\
0.18 \\
0.18 \\
0.32 \\
0.14 \\
0.03 \\
0.07\end{array}$ & $\begin{array}{r}0.25 \\
0.05 \\
0.29 \\
0.29 \\
0.29 \\
0.08 \\
0.11 \\
0.14 \\
0.14 \\
-0.05\end{array}$ & $\begin{array}{l}0.28 \\
0.32 \\
0.42 \\
0.32 \\
0.32 \\
0.36 \\
0.17 \\
0.17 \\
0.21\end{array}$ & $\begin{array}{r}0.32 \\
0.21 \\
0.32 \\
0.35 \\
0.28 \\
0.31 \\
0.31 \\
-0.01\end{array}$ & $\begin{array}{r}0.03 \\
0.46 \\
0.46 \\
0.16 \\
0.54 \\
0.20 \\
-0.13\end{array}$ & $\begin{array}{l}0.35 \\
0.13 \\
0.16 \\
0.08 \\
0.08 \\
0.35\end{array}$ & $\begin{array}{r}0.35 \\
0.28 \\
0.31 \\
0.31 \\
-0.01\end{array}$ & $\begin{array}{llll}0.39 & & \\
0.31 & 0.11 & \\
0.08 & 0.11 & 0.01 \\
0.11 & 0.01 & 0.04\end{array}$ \\
\hline & & PTA & RTW & FF & IR & SL & $\mathrm{CO}$ & FA & DZ & SP & LI & NO & IN & HE & CR & TT BU DE \\
\hline
\end{tabular}

* = significant at $\mathrm{p}=0.05$ (two-sided). Significances are indicated for the correlations in the first two columns of the table only.

two components only, these two components were extracted for further rotation and interpretation. Figure 1 shows the results after a quartimax rotation. The loadings on the two dimensions (factors) are given in table 4. Factor 1, on which all questionnaire items load positively, can be interpreted as a general "having complaints" dimension. It will be referred to as the Complaining factor. PTA and RTW have the highest loadings on factor $2(0.80$ and 0.70 respectively), and hence this dimension bears upon the severity of the injury. It will be called the Severity factor. In fig 1 a "dubious" area of loadings between 0.20 and 0.40 on factor 2 has been delineated to discriminate complaints with a definite relationship to severity from those that have not. All four impairment complaints

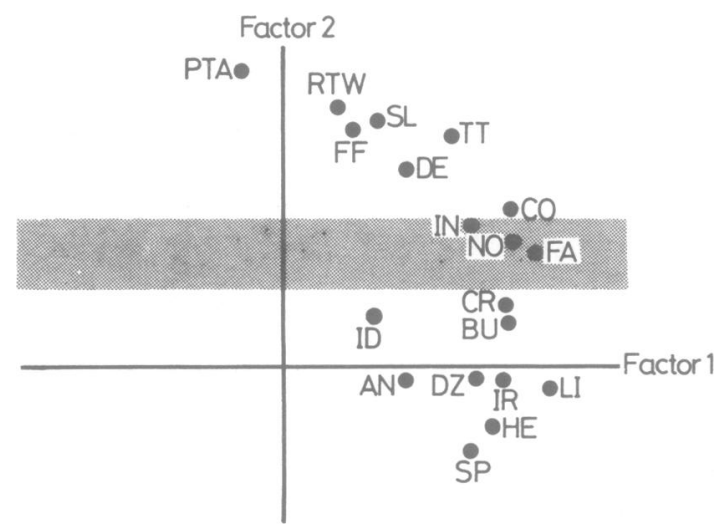

Fig 1 Plot of table 4; principal components of PTA, RTW and residual complaints. The analysis was based on intercorrelations. The principal components (factors) were quartimax rotated. For abbreviations see table 4. lie above this area. The only other complaint that is apparently also related to Severity is "depressed mood". With the exception of "indifference" and possibly "anxiety", the complaints that are clearly unrelated to the Severity factor (that is below the dubious area) all exhibit an air of hypersensitivity too the outside world. Accordingly, they can be labelled as "intolerances". It is precisely these complaints which have inspired many investigators to discuss posttraumatic ailment in terms of neurosis. "Indifference" and "anxiety" were atypical complaints (table 1) and do not really fit in the two-factor solution; their loadings on both factors were very small.

Table 4 Principal components of PTA, RTW and residual complaints as indicated by 52 patients The factors are quartimax rotated; the intercorrelation matrix of Table 3 was used

\begin{tabular}{llcr}
\hline & & \multicolumn{2}{l}{ loading on } \\
\cline { 3 - 4 } & & FACTOR I & FACTOR 2 \\
\hline & PTA & -0.13 & 0.80 \\
& RTW & 0.14 & 0.70 \\
FF & forgetfulness & 0.19 & 0.63 \\
IR & irritability & 0.59 & -0.03 \\
SL & slowness & 0.25 & 0.66 \\
CO & poor concentration & 0.61 & 0.42 \\
FA & fatigue & 0.68 & 0.31 \\
DZ & dizziness & 0.52 & -0.03 \\
SP & increased need of sleep & 0.51 & -0.24 \\
LI & intolerance of light & 0.72 & -0.07 \\
NO & intolerance of noise & 0.61 & 0.33 \\
IN & loss of initiative & 0.51 & 0.38 \\
HE & headache & 0.57 & -0.17 \\
CR & crying more readily & 0.60 & 0.16 \\
TT & inability to do two things sim. & 0.44 & 0.62 \\
BU & intolerance of bustle & 0.61 & 0.12 \\
DE & depressed mood & 0.32 & 0.53 \\
AN & more anxious & 0.33 & -0.05 \\
ID & indifference & 0.24 & 0.13 \\
\hline
\end{tabular}




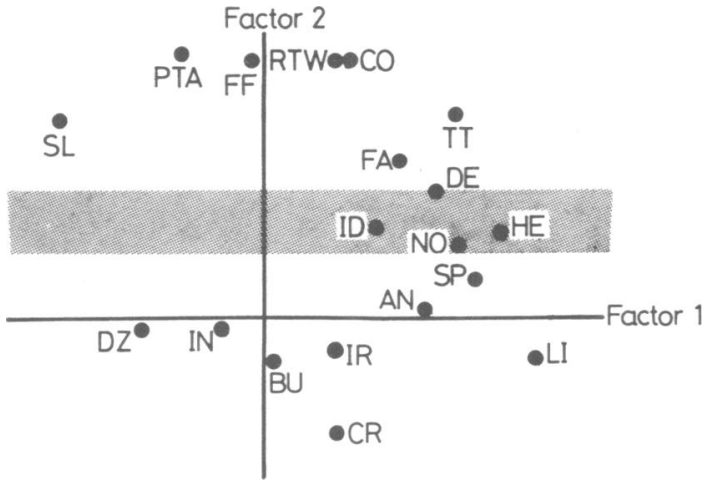

Fig 2 Principal components of $P T A, R T W$ and residual complaints as indicated by relatives of 18 patients. Plot of the loadings; the components (factors) were quartimax rotated.

\section{A validation based on relatives' reports}

Using the same questionnaire, relatives of 18 patients were also interviewed to explore their view of any residual complaints of the patients. Their responses were analysed to find out whether their opinions would relate in the same way to PTA and RTW as was depicted in fig 1 . Figure 2 shows the analogue of fig 1 . Despite the extremely small data set, and therefore very unreliable intercorrelations, the same general structure with respect to the Severity factor is apparent. Factor 1 is not reproduced satisfactorily.

\section{When is a closed head injury "very severe'?} In the well-known Russell classification ${ }^{12}$ a PTA duration of one week is used to differentiate between a severe and very severe concussion. Having established that the severity of the injury, as measured in terms of PTA duration, is correlated with the occurrence of impairment complaints and with RTW, the usefulness of this dichotomy can be evaluated. Below the point of 7 days the frequency of the impairment complaints should be relatively low, and above it steeply increasing. A similar pattern should be apparent with respect to RTW.

Figure 3 presents percentages and frequencies of impairments. As can be seen, the one-week bound is a reasonable one. After some trial and error, however, a better cut-off in our sample could be found at a higher PTA level, namely at the "unlucky" number of 13 days. The histograms shown in fig 3 were drawn in such a way as to include both cut-off points, as well as to ensure that each PTA-class would contain approximately the same number of individuals. Noteworthy is the sharp increase in the "forgetfulness" and "slowness" complaints. The complaint about divided attention ("Do you have more trouble in doing two things simultaneously, since the accident?") is not present for PTA durations shorter than or equal to one week.

Table 5 shows the correlations of the four impairment complaints and RTW with (a) PTA in days, (b) PTA dichotomised according to Russell and (c) PTA dichotomised according to the "unlucky" number classification. As far as impairment complaints are concerned, this latter classification not only appears superior to the Russell classification in this sample, but likewise to the continuous PTA variable. Only a slight decrease in the correlation with RTW arises from using the unlucky number classification instead of PTA in days.

\section{Discussion}

Two years after the injury, $84 \%$ of the patients still reported some residual deficit in their psychological functioning. The five complaints most frequently mentioned in the present sample (table 1) are in close agreement with those reported by other investigators, ${ }^{56}$ whose studies covered follow-up periods of 6 and 12 months. Hence, unlike the polymorphous symptom picture, presented by minor head injuries, ${ }^{1}$ severe head injury is characterised by rather typical residual complaints. The fact that complaints about memory were most frequent illustrates once more the importance of using specific, standardised memorytests for the assessment of head-injured people. The value of such tests has been convincingly demonstrated in the last decade. ${ }^{14-16}$ Likewise, the results concerning mental slowness and inability to divide attention over two activities are in agreement with evidence on the reduction of information processing capacity after head injury. ${ }^{17-20}$ Though the complaint relating to a divided attention deficit was not very frequent, it did correlate highly with RTW (table 3 ) and was not present in patients with a PTA shorter than 7 days (table 5). This finding can therefore be considered to be clinically significant. At variance with the layman's ideas, the headache complaint showed a relatively low frequency.

Severity of injury was expressed in two ways: duration of PTA served as a neurological index of severity while RTW was interpreted as a social index of severity. PTA appeared to be a reasonably good predictor of a patient's chance to resume his former work or study and this finding lends support to Russell's statement ${ }^{12}$ that PTA is a sensitive and reliable index of severity. The correlation of 0.52 found in the present study is fairly satisfactory, particularly in view of the fact that the variable RTW must comprise a considerable amount of "noise". Whether a patient can resume his or her work does not solely depend on the degree of recovery. The nature of the previous work, the willingness of the employer to adapt the 
(a) Forgetfulness

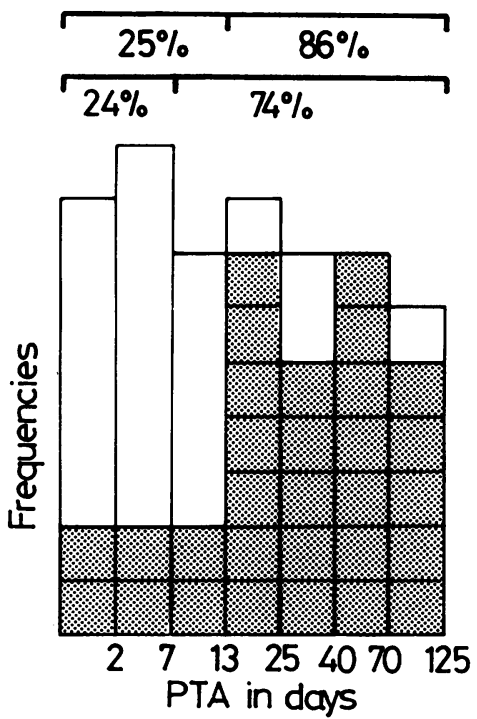

(d) Inability to do two things simultaneously
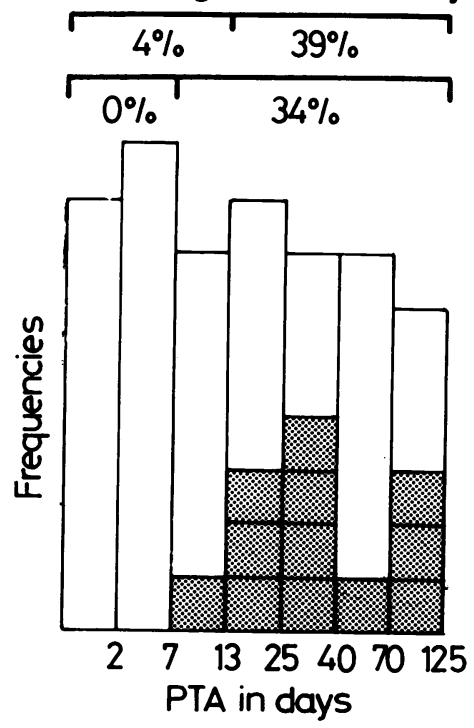

(b) Slowness

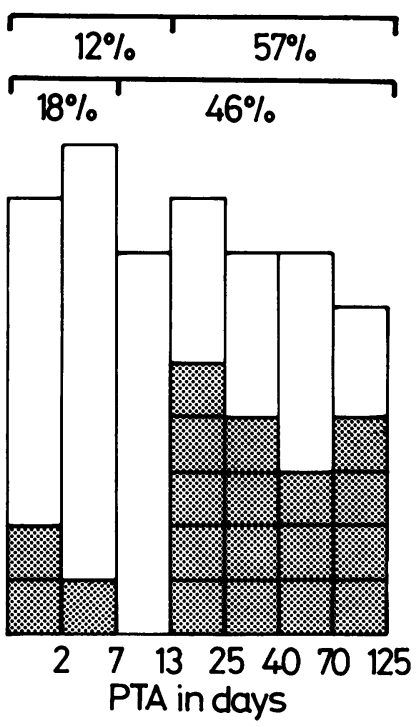

(e) Return to work

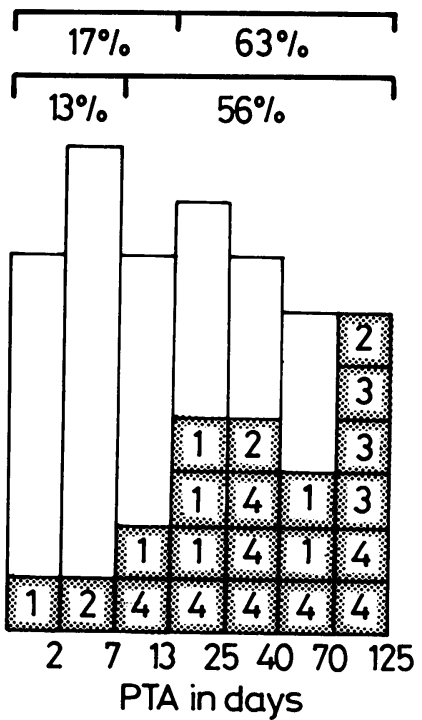

(c) Poor concentration
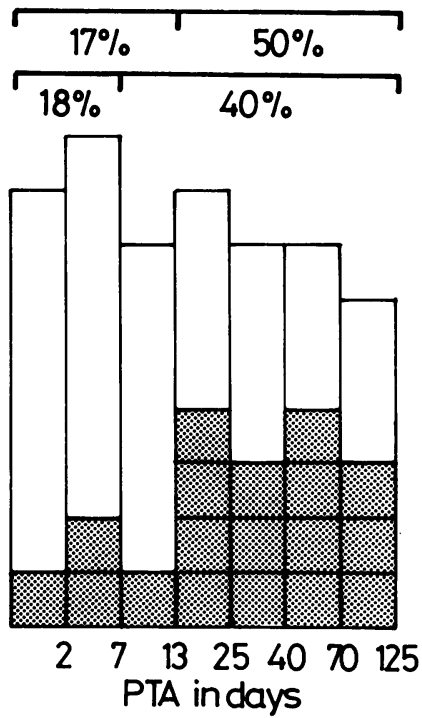

Fig 3 Percentages and frequencies of impairment complaints and RTW in relation to PTA. Each square in a histogram represents one patient. A shaded square indicates that the patient endorsed this complaint, or in the case of $R T W$, had not resumed his or her former work. PTA classes are indicated with their endings, for example class 7 is the class of 3 to 7 days. For $R T W(E)$ the numbers in the squares refer to the coding as described in the Method section, in which 4 indicates that the patient is not working at all. Above the histograms, percentages of complaints are given in the broad PTA categories according to Russell's classification ( 7 days) and to the "unlucky number" classification (13 days). 
Table 5 Correlations of three severity measures, based on $P T A$, with the four impairment complaints and RTW

\begin{tabular}{llll}
\hline & $\begin{array}{l}\text { PTA } \\
\text { in days }\end{array}$ & $\begin{array}{l}\text { Russell } \\
\text { dichotomy }\end{array}$ & $\begin{array}{l}\text { 13 day } \\
\text { dichotomy }\end{array}$ \\
\hline Forgetfulness & 0.55 & 0.48 & 0.61 \\
slowness & 0.37 & 0.27 & 0.46 \\
poor concentration & 0.28 & 0.25 & 0.35 \\
inability to do two things & 0.37 & 0.38 & 0.42 \\
Return To Work & 0.50 & 0.40 & 0.44 \\
\hline
\end{tabular}

working situation to the reduced abilities of the patient, the degree of unemployment in the society as a whole, as well as the motivation of the subject, all play a role.

The total number of complaints did not correlate appreciably with the measures for severity of injury. When the individual items of the questionnaire were examined, however, it appeared that complaints concerning impairments were indeed related to PTA and RTW, whereas complaints about intolerances were not. Hence an important conclusion from this study is, that PTA and RTW can only be considered as unambiguous measures of severity in relation to complaints patients make about cognitive impairment.

The question can be raised as to whether intolerances in general should be considered as neurotic, or at least as non-organic in origin. Before discussing this point further, it must be stressed that these complaints were not only characteristic of patients at the milder end of the range of severity, but were presented by patients with injuries at all grades of severity. Two alternative explanations can be given for the absence of a relationship between the intolerances and severity. Firstly, the possibility exists that certain aspects of the head injury, not accounted for by PTA, are responsible for the intolerances. Secondly, the absence of a positive relationship might be explained by means of the coping hypothesis. This hypothesis has been put forward by Goldstein and Hillbom, ${ }^{21} 22$ and has been elaborated by van Zomeren et al. $^{23}$ It states that "neurotic" symptoms may result from a chronic effort by the patients to compensate for their cognitive deficits. This effort is an answer to the demands made by the social environment and the patient's own standards. Such demands are made specifically to those patients who are not visibly handicapped and whose injuries are not considered to be so severe as to prevent a complete resumption of previous activities. When the cognitive functions are not yet completely recovered, the resulting stress may lead to intolerances as secondary symptoms, especially in the less severely injured patients. The net effect in the sample as a whole may be a zero correlation between complaining and severity of injury.

When residual complaints and RTW are used as criteria, the Russell dichotomy of severe versus very severe concussions appears to work well. This classification was based on clinical experience and though the empirical data presented here support its usefulness, a somewhat better dichotomy was nevertheless found, with 13 days instead of 7 as the cut-off point. Apart from sampling contingencies, it is possible that our criteria for marking the end of PTA were more rigid than those applied by Russell. However, we see no reason to assume such differences in scoring PTA, and therefore a more optimistic explanation may be offered. The Russell classification was derived from clinical studies up to approximately 1960 , while the unlucky number dichotomy was based on the complaints of patients admitted in 1978 and 1979. In these intervening years, medical and psychological care have been improved, and the shift from 7 to 13 days suggested in this study could well be a result of these improvements.

We thank JMF ten Berge, WH Brouwer, G Collins, BG Deelman, J Jackson, JM Minderhoud and RJ Saan who contributed in various ways to this study. Likewise, we are grateful to the patients who served as subjects.

Note $24-27$

Some authors (for example Horst) have expressed reservations with respect to the validity of factor analytic methods with dichotomous data, that is on phi coefficients. However, others have discussed the topic without mentioning these doubts (for example Nunnally, p. 351). Extensive discussions are found in Rummel (p. 303-305) and Ten Berge. The major point is that the "yes" proportions p with which the dichotomous variables occur will differ, and thereby produce upper bounds to the maximally possible phi coefficients (phi max) that may be much smaller than 1. Since, however, (1) the phi-max minus phi-found values are considerable in this study, (2) the $p$ values are far from extreme, and (3) only the two major principal components are used, a very distorted factor solution is not to be expected on the basis of this reasoning. Borgatta gives further empirical evidence on the non-distorting effects of using phi coefficients. Furthermore, the major use of the analysis performed concerned the magnitude comparisons of the loadings of complaints on the Severity factor. This is clearly a continuous variable, since it is determined to a large extent by the continuous variables PTA and RTW. These loadings are point-biserial correlations and possible distortions due to upper bounds will be slight, given the $p$ values and loadings found in the study. Nunnally (p. 146) presents a relevant graph. 


\section{References}

${ }^{1}$ Lidvall HF, Linderoth B, Norlin B. Causes of the postconcussional syndrome. Acta Neurol Scand 1974; 50, suppl. 56.

${ }^{2}$ Rutherford WH, Merrett JD, McDonald JR. Sequelae of concussion caused by minor head injuries. Lancet 1977;1:1-4.

${ }^{3}$ Minderhoud JM, Boelens MEM, Huizenga J, Saan RJ. Treatment of minor head injuries. Clin Neurol Neurosurg 1980;82-2:127-40.

${ }^{4}$ McLean A, Temkin NR, Dikmen S, Wyler AR. The behavioral sequelae of head injury. $J$ Clin Neuropsychol 1983;5-4:361-76.

${ }^{5}$ Oddy M, Humphrey M, Uttley D. Subjective impairment and social recovery after closed head injury. $J$ Neurol Neurosurg Psychiatry 1978;41:611-6.

${ }^{6}$ McKinlay WW, Brooks DN, Bond MR, Martinage DP, Marshall MM. The short-term outcome of severe blunt head injury as reported by relatives of the injured persons. J Neurol Neurosurg Psychiatry 1981;44:527-33.

${ }^{7}$ Miller H. Accident neurosis. Br Med J 1961;1:919-25.

${ }^{8}$ Miller H. Mental after-effect of head injury. Proc $R$ Soc Med 1966;59:257-61.

${ }^{9}$ Kelly R. The post-traumatic syndrome: an iatrogenic disease. Forensic Sci 1975;6:17-24.

${ }^{10}$ Merskey H, Woodforde JM. Psychiatric sequelae of minor head injury. Brain 1972;95:521-8.

${ }^{11}$ McKinlay WW, Brooks DN, Bond MR. Postconcussional symptoms, financial compensation and outcome of severe blunt head injury. $J$ Neurol Neurosurg Psychiatry 1983;6:1084-97.

12 Russell WR. The Traumatic Amnesias. Oxford, 1971. Oxford University Press.

${ }^{13}$ Rummel RJ. Applied Factor Analysis. Evanston, Ill: Northwestern University Press, 1970.

${ }^{14}$ Brooks DN. Memory and head injury. J Nerv Ment Dis
1972; 155:350-5

${ }^{15}$ Schacter DL, Crovitz HF. Memory function after closed head injury: a review of the quantitative research. Cortex 1977;13:150-76.

${ }^{16}$ Deelman BG. Memory Deficits after Closed Head Injury. INS European Conference 1977, Oxford. INS Bulletin No 1.

${ }^{17}$ Miller E. Simple and choice reaction time following severe head injury. Cortex 1970;6:121-7.

${ }^{18}$ Gronwall DMA, Sampson H. The Psychological Effects of Concussion. Auckland, 1974. Auckland University Press.

${ }^{19}$ Van Zomeren AH, Deelman BG. Long-term recovery of visual reaction time after closed head injury. $J$ Neurol Neurosurg Psychiatry 1978;41:452-7.

${ }^{20}$ Van Zomeren AH. Reaction Time and Attention after Closed Head Injury. 1981 Lisse, Swets and Zeitlinger.

${ }^{21}$ Goldstein $\mathrm{K}$. The effects of brain damage on personality. Psychiatry 1952;15:245-60.

${ }^{22}$ Hillbom E. After effects of brain injuries. Acta Psychiat Scand 1960; suppl. 142.

${ }^{23}$ Van Zomeren AH, Brouwer WH, Deelman BG. Attentional deficits: the riddles of selectivity, speed and alertness. In: Brooks DN, ed. Closed Head Injury-Psychological, Social, and Family Consequences. Oxford. Oxford University Press 1984.

24 Borgatta EF. Difficulty factors and the use of $r_{p h}$. Journal of General Psychology 1965;73:321-37.

${ }^{25}$ Horst P. Factor analysis of data matrices. 1965, New York, Holt. Ch. 22

${ }^{26}$ Nunnally JC. Psychometric Theory (2nd Ed.). 1978, New York, McGraw-Hill.

${ }^{27}$ Ten Berge, JMF. Difficulty factors, distribution effects, and the least squares simplex data matrix solution: Educational and Psychological Measurement, 1972;32, 911-20. 